\title{
The HIV Infection: Clarification of Its Legal Classification of Transmission and Measures to Protect Societies from Burdening Caused by Social and Medical Care Services for the Coming Decades
}

\author{
Reinhard H. Dennin 1*, Arndt Sinn² \\ ${ }^{1}$ Former: Department of Infectious Diseases and Microbiology, University of Luebeck, UKSH, Campus Luebeck, Luebeck, Germany \\ ${ }^{2}$ Centre for European and International Criminal Law Studies (ZEIS), University of Osnabrueck, Osnabrueck, Germany \\ Email: *rh.dennin@t-online.de
}

How to cite this paper: Dennin, R.H. and Sinn, A. (2019) The HIV Infection: Clarification of Its Legal Classification of Transmission and Measures to Protect Societies from Burdening Caused by Social and Medical Care Services for the Coming Decades. World Journal of AIDS, 9, 33-48. https://doi.org/10.4236/wja.2019.92004

Received: April 5, 2019

Accepted: May 31, 2019

Published: June 3, 2019

Copyright $\odot 2019$ by author(s) and Scientific Research Publishing Inc. This work is licensed under the Creative Commons Attribution International License (CC BY 4.0).

http://creativecommons.org/licenses/by/4.0/

\begin{abstract}
This article addresses issues regarding the transmission of HIV; without the combination antiretroviral treatment (cART), HIV causes a fatal outcome of those infected in most cases. First, legal issues: For years, controversial discussions have dealt with the subject of the legal classification of HIV infection, such as "... criminalization of HIV exposure might limit access to and uptake of HIV prevention services..." Based on the rule of law of a constitutional state, we explain the legal principles that serve to protect the legal rights of its citizens. The state has to protect its citizens from harm by other people. The prosecution and conviction of a specific person for a proven HIV infection are legal. Therefore, general decriminalization of HIV infection would undermine the right of thereby harmed citizens to compensation. Second, HIV prevention strategies: Based on the Test and Treatment Strategy (TASP $)^{1}$, controlled studies were undertaken to find out which framework conditions could improve their benefit. We outline concepts that can help to curb the still ongoing spread of HIV: By providing early HIV diagnosis and ongoing HIV care services as part of updated education and prevention campaigns. Also, concerted, comprehensive campaigns are required to demonstrate further impacts of HIV infection: Both on the quality of life of infected individuals due to the development of non-communicable diseases and the increasing burden to societies as a whole.
\end{abstract}

${ }^{1}$ Vernazza P. et al. Schweizerische Ärztezeitung, 89, 165-169 (2008).

https://doi.org/10.4414/saez.2008.13252. This concept bases on treatment with antiretroviral drugs, named "combination antiretroviral treatment (cART)." 


\section{Keywords}

HIV Infection, Criminalization, Decriminalization, Government Obligations, Unswayable People, Early Testing, HIV Care, Social Burdening

\section{Introduction}

\section{1) Facts}

a) A statement of the UNAIDS indicates that there is a "prevention crisis" in the context of "... a precarious point" . The addressed "complacency" of people who come forward with the HIV incidences is a serious part of the problem [1].

b) The warning of the WHO "Europe's HIV epidemic growing at an alarming rate" [2] targets a correct fact; it should promote political decision-makers to reconsider their inappropriate/widely unrealistic prevention concepts. The development of the HIV epidemic in Russia, see [3] and at the global level see Merson et al. [4].

\section{2) The Reasons Responsible for This Development of HIV Spreading Behavioral Issues}

a) The statement of the ECDC/WHO "Although HIV is preventable through effective public health measures, significant HIV transmission continues in Europe" [5] reveals the problem; it reflects the in effect failed HIV prevention strategies and public health measures of the past concerning to real epidemiological facts. Prevention campaigns basing only on New Public Health tenets can try to influence people in general and, in particular, those belonging to the at-risk target people to behave responsibly according to the correct messages. The essential facts to be considered are: The HIV prevention strategies and public health measures have ignored both the unswayable HIV-naive as well as the HIV-infected people; many of them are not ready to cooperate with the right prevention messages. Those already infected with HIV are directly related to the ongoing spread of HIV. For a variety of reasons, they are unwilling to bow to the recommendations for restrictive behavior in compliance with the correct prevention campaigns and laws; many of them intentionally violate the rule of not compromising the physical integrity of HIV-naive partners; excluded here are those people who suffer from, e.g. different psychosocial risk factors. Such situations can make it impossible for them to follow the right prevention messages and to determine their individual and medical care condition.

\section{Biomedical Approach}

b) The HIV infection is not self-limiting; without a lifelong intervention with cART, it leads to death several years after the stage of AIDS in most cases; a particular situation concerns the elite controllers. Only with cART, it is possible to improve both the status of the immune system and the condition of health; al-

${ }^{2}$ https://www.unaids.org/en/resources/presscentre/pressreleaseandstatementarchive/2018/july/milesto-go. 
though often connected with a reduced quality of life due to "advanced HIV disease" [6], many of these patients can achieve an almost normal life expectancy. Neither the period from the person-to-person transmission of HIV to the death (years), nor the medication with cART fundamentally alter the fact that this is a homicide.

c) In spite of the invention of the TASP strategy, problems emerged.

Statements by renowned organizations refer to: 1) the hazardous situation of the yet uncurbed HIV epidemic in most countries, and 2) the widely inherent lack of understanding at the level of decision-makers of the various driving forces of the ongoing spread of HIV. The latest report from UNAIDS confirms this situation regarding the global decline in new HIV infections to "...1.8 million (1.4 - 2.4 million) in 2017. However, progress is far slower than whatis required to reach the 2020 milestone less than 500000 new infections" [7]. The report of the WHO addresses the same developments [8]. Apart from difficulties with financial support, there are various reasons for this insufficient decline in new HIV infections; selected remarkably for examples: 1) in high-income countries, the complacency and carelessness of risk-prone people, who blindly trust to the effectiveness of the cART available in the case of an HIV infection, and 2) problems basing on the infrastructure in low-income countries to provide CART.

\section{Legal Aspects}

d) Relying on the principles of law such as "You shall not harm/kill another person" is irrelevant to the vulnerable persons mentioned here.

e) Moreover, their "prevention-contrary" behavior does not follow the legal stipulation in the German constitution and the constitutions of other countries.

f) The "Policy Options Paper" by UNAIDS [9] weighs up different circumstances regarding the criminalization of HIV infection. The press release of "Leading Researchers" [10] focus on various issues of the HIV infection and points out “... that phylogenetic analysis alone cannot prove beyond reasonable doubt that one person infected another although it can be used to exonerate a defendant." ${ }^{3}$ However, what about the responsibility of people-Who can and do transmit a mostly fatal infection-To not harm another person? According to the German Constitution, the HIV infection of another person is considered a killing offense. This clause applies to countries where the bodily injury resulting in the death of another person is not permitted. In these cases, the public prosecutor's office requires the individual's demand for punishment of the infecting person. This fundamental right must not be belittled.

\section{Co-Infections Alongside with HIV- and Vice Versa}

g) Furthermore, in addition to HIV infection with its exceptional status, there is a strange situation concerning other sexually transmitted infections (STIs); the infection of another person with both the Hepatitis C virus (HCV) and/or Treponema pallidum (syphilis) have severe additional health consequences and challenges for societies too; but these are not considered in the same context as ${ }^{3}$ See below, Chapter "The problems in the application of law". 
HIV HIV-Why? The exceptional status for HIV has not applied to HCV and Treponema pallidum, although these pathogens partly share the same routes of person-to-person transmission.

3) The State of Affairs-But the Evidence of the Expected Effect?

a) The ECDC [11] in a short review reported on issues of the impact of "criminalization of, e.g. HIV exposure" and the "uptake of HIV services among key populations." The report by the ECDC endeavors to clearly show the adverse impact of criminalization on HIV prevention services. The Dublin Declaration on a Partnership to fight HIV/AIDS in Europe and Central Asia focuses above all on the rights of those infected [12]. However, what are their duties?

b) The relevant notes in this context are: 1) "Criminalization can undermine the delivery of essential HIV services to key populations"; 2) "Responses indicate that in a significant proportion of countries, criminalization of HIV exposure and HIV non-disclosure is thought to limit access to and uptake of HIV services among key populations"; 3) "Eight EU/EEA and seven non-EU/EEA countries reported that criminalization of HIV exposure might limit access to and uptake of HIV prevention services and four EU/EEA and six non-EU/EEA countries reported that criminalization of HIV non-disclosure might have the same effect" [11] [13].

\section{4) Our Aims:}

Firstly, we focus on German criminal law and, secondly, on selected measures from international studies that may help to curb the yet ongoing spread of HIV.

\section{Task and Function of Criminal Law}

In a constitutional state, the law has the task to contribute to the securing of social peace. The function of it is to regulate abstractly specific facts of living and to create a foreseeable solution beyond any possible arbitrariness. Criminal law has an extraordinary task to play here, such as setting the criminal liability of situations and to convict offenders. ${ }^{4} \mathrm{~A}$ modern understanding of criminal law is not about a pure Talion in the sense of retribution of the same. It is rather a matter of stabilising the law because if a realisation of a penal provision remains without sanction it has a destabilising effect. Citizens would no longer trust the enforcement of the law and potential offenders would no longer take the law seriously. The destructive strength of this mechanism should have become clear. Naturally not part of stabilising the law-Thus prevention-Is that all norm violations are prosecuted. This idea already fails thereon that not all crimes become known or can be proved. A constitutional state has to at least contribute as much as necessary to stabilising the law so that the citizen can see that the law does not only have a symbolic character but really applies. Therefore, a behavior-guiding function of criminal law cannot be disputed.

Criminal law serves the protection of legal rights. Abstract issues will be formed in criminal offenses which should be avoided. It is not easy to answer ${ }^{4}$ Vgl. Gropp, Strafrecht Allgemeiner Teil, 4. Aufl. 2015, \$ 1 Rn. 143. 
which interests should be protected as (criminal) legal rights. Secured knowledge is that personal legal rights, such as body, life, freedom and property should be protected with the means of criminal law. This recognition results from social value, because who would dispute that these legal rights are not in need of protection and that their guarantee is not a basis for a peaceful society. Not least this value is also expressed in the constitution of the Federal Republic of Germany because the state guarantees these interests in Art. 2 and 14 of the constitution of the Federal Republic of Germany. Of course, fundamental rights constitute a defense of the citizen against the state, though the state has to observe protective duties for its citizens and protect these rights through criminal law. These protective duties determine the task of the state, to protect its citizens from injuries by other citizens. To achieve this, the state has to take relative measures, if necessary to ensure criminal law protection. What emerges from this is the obligation to protect at least predominantly important legal interest such as life not just from determining state aims but concretely from the fundamental rights. ${ }^{5}$

\section{The Protection of Life and of Physical Integrity through Criminal Law}

From the tasks and the function of (criminal) law, it follows that life and physical integrity should be protected. The legislator utilises a control technology that, apart from casuistry, describes abstract actions that violate these goods and should be punished. In the centre of these penal provisions to protect life and physical integrity are the offenses involving bodily injury and homicides. In the description of what should be punished as personal injury or killing, the German legislator renounced the need to include details to the regulations with the $\$ \$ 223,229,212$ and 222 StGB (intentional bodily injury, negligent bodily injury, intentional killing and negligent killing). This leads to, that every bodily injury or killing caused by the described action, committed with intention or negligently, which is not justified, triggers legal consequence as a punishment. The resulting breadth of possible application of the law on various life circumstances is due to the fact that the legislator does not know every possible behavioral pattern which could lead to an injury and the law could become rigid and also incomplete if one would follow a detailed control technology. Rather the legislator has to choose abstract formulations in the limits defined by the principle of legality (Art. 103 section 2 GG) to comply with its protection obligation and to remain capable of acting. If therefore the intentional or negligently caused bodily injury or killing is caused with a knife, poison, a punch or with a transmission of the HI virus, it is within the legitimate protection concept of the legislator. If now the other side requires that especially the transmission of the HI virus should be decriminalised, it must be explained why, particularly in these cases, the legislator should or even can withdraw out of his obligation to protect. It remains open why in these cases the citizen should lose their criminal protection, but there is no apparent legitimate interest to take this specified area of infringement out of the scope of protection of the stated penal provisions. In

${ }^{5}$ Vgl. Schwangerschaftsabbruch und BVerfGE 115, 118. 
this context, it must not be ignored that the term "decriminalisation" requires that the transmission of a HI virus was "criminalised". However precisely this is not the case in Germany, then every intentional or negligently caused bodily injury or killing is punishable, no matter by what means it was caused. In Germany, there is no particular criminal offense which punishes the transmission of a HI virus. The valid criminal offenses for the protection of physical integrity and life are in this respect value-neutral. They conform to the type of injury and killing. With them no specific behavior pattern, no specific lifestyle, no passion, illness or attitude is discriminated against. It is always about the commandment that the physical integrity and life of others should not be infringed. At the level of this prohibition there can be no doubt that intentional or negligent injury through the transmission of HIV should entail consequences in accordance with criminal law. The opposite view alters the basic nature of a peace order by law. After all, if one were to obtain a partial decriminalisation, it would have to be explained to the citizen why he is losing his criminal-law protection after he has become infected intentionally or negligently provided he was unaware of the other person's infection. Why should he have to ensure his self-protection, when the infected person has the choice to take the necessary protective measures or to inform the other person about the danger of contact. Only then is it possible for the other person to decide about the extent of contact and the seriousness of the risk. Without this knowledge, the unknowing person puts them self in the hands of the risk carrier, without knowing the scale of the risk in his decision. It does not contradict the assumption that the unknowing person could have sufficiently protected himself. Then, there is no law for self-protection, which would nullify the obligation of the infected person to prevent the injury of other persons.

\section{The Problems in the Application of Law}

Now that it has been proved that a protection concept for physical integrity and life constructed on the German constitution cannot be broken, through the decriminalisation of certain behavioral patterns in the current protection concept in Germany. But there are some practical specific features to consider due to the characteristics of the HIV infection which make the protection concept appear much vaguer than on a pure interdiction plane.

As seen a person who causes intentional or negligent bodily injury or death through the transmission of the HI virus will be punished according to the stated criminal offenses. These criminal offenses assume that the injury or death was caused. In other words, there is evidence proving the causality that the transmission was effected specifically from this person to another person. Practically this is difficult as changing or numerous sexual partners mean that the transmission chain cannot always be determined without a doubt. While in some cases modern genome analysis can provide clarification, it is not successful in all cases. After a failed proof of causality, it is still possible to hold the person accountable for attempted bodily injury or homicide [14]. Herewith the problem of the 
causal contribution has been solved, assuming that the infected person acted with the knowledge of his own infection and without protective measures, moreover it is necessary that the uninfected person acted without knowledge of the other person's infection. Only in cases where the infected person acted with knowledge of his own harmfulness is it possible to talk of intentional behavior and an attempted injury can only be committed intentionally. If evidence of intentional behavior cannot be proven the person must be acquitted. If the person took protective measures to prevent the transmission of the HI virus, intentional behavior can be negated as the infected person should be able to rely upon the fact that his partner does not become infected. The question of intent is problematic when it is questionable if the infected person can also rely upon the absence of infection when protection is provided by taking antiviral medications intended to reduce the viral load and therefore the risk of injury. In these cases, it depends on how much the risk of infection is reduced and to what extent the infected person can rely upon the fact that the residual risk does not result in an infection. This is ultimately an issue of the facts. Withdraw an abstract consideration and a decision must be made on a case-by-case basis. If viruses cannot be detected in the blood it can be assumed that even in the unlikely case of an infection intentional behavior must be excluded.

\section{Conclusion 1}

In the legal practice in Germany one can certainly not speak of criminalisation of HIV-transmission, because in many cases the application of the penal law dogmatic doctrine de facto excludes a punishment. The specific characteristics of HIV-infection and the application of penal provisions to protect physical integrity and life result in a complex intertwining dogmatic construction which uses a filter function to avoid a disproportionate interference of criminal law in a citizen's civil rights and liberties. To maintain a peace order through law also means that the order not to injure or kill others cannot be partially retracted. In point of fact this order is equal for everyone. Instead of calling for a decriminalisation the emphasis should be strongly focused on the relationship between knowledge and unawareness by the transmission of HIV. Only those who know of the danger of contact can protect themselves. Consequently, it is both the duty of the infected person and the uninfected person to provide and exchange this knowledge and to bring this into balance during contact.

\section{What Are the Barriers to Preventing the Further Spread of HIV, and Thus Counteracting the Goal of UNAIDS?}

1) HIV Prevention Strategies

a) Countries which follow the NPH strategies trust concepts basing on information about the HIV infection, both regarding the routes of HIV transmission and the disease AIDS. The communication operates by right messages on how to avoid risks of HIV transmission; they get distributed by mass communication both for the general public and vulnerable people. However, these messages 
emphasize a "right of self-determination", that is, without frameworks to control the misdemeanours of many people; such a strategy cannot work thoroughly and long-lasting.

b) The accompanying measure Treatment as Prevention is a biomedical approach using antiretroviral drugs both to suppress the HIV replication in HIV infected people thereby improving their immune status and to reduce their infectiousness. But reports on "disparities" reveal the deficits in adherence at different levels [15].

c) However, even these kinds of combined strategies/measures have basically failed in their goal to curtail the spread of HIV. Otherwise, the UNAIDS report for 2017 wouldn't show 36.9 million people living globally with HIV and 34.4 million people have died since the start of the epidemic [16].

d) How could this happen? All those HIV-infected people had the chance/opportunity to behave correctly in line with the prevention campaigns and following the adherence when on cART. The designers of the liberal strategies and the regional structured concepts have ignored, e.g. i) the uncountable diversity of people following various lifestyles regarding cultural or regional norms instead of obeying the correct messages of the prevention campaigns; ii) the lacking ability of too many people to understand accurate messages regarding safer sex and safe use; iii) their willingness or not to subordinate their behaviour to them, and iv) the motivations of those unswervingly driven by selfish gain to act out their sexually motivated lifestyles, usually referred to as "sexually guided compulsivity."

e) Consequences: The experiences with sexual self-determination without any control have proved to be ineffective to halt the spread of HIV in most countries.

2) In the following chapters, we highlight issues which must be considered in altered prevention campaigns trying to hold up the yet ongoing spread of HIV. The methodological approach was to check scientific literature using appropriate keywords. The primary emphasis was placed on articles that reflect at the international level a broad spectrum of the problems addressed here.

a) The ECDC already published in 2015 issues that urgently need to be realized by political decision-makers and other both official and non-official organizations, e.g. voluntary partner referral, condom use, and confidential HIV and STI counseling and testing services [17]. That's correct; however, their implementation.

b) Current strategies do not consider the complex web of factors of the high diversity of people concerned [18] [19] [20]. The "non-disclosure" behavior among at-risk people creates a strange situation [21].

i) The situation about HIV infection and upcoming new circumstances such as organized settings for at-risk people has changed the field of problems. There is a need for multilevel interventions by updated prevention campaigns with messages covering the broad spectrum of former and new target people. They must include notes which for counseling uncover the mutual impacts of HIV and other STI and the co-morbidities whose consequences for the health of 
those affected augment with age. The increasing rates of Syphilis in Germany [22] and other countries, Hepatitis C virus infections, e.g. in certain countries in Europe [23] and the consequences for the health of those concerned [24] are alarming. These circumstances relate the lacking knowledge about the HIV infection, in particular among younger people [25]. Increasing awareness through innovation must be urgently established [26]. Furthermore, although not a problem of a massive HIV transmission is the yet not really considered homeless people, in particular, the older ones: If HIV-positive but cART-naïve ones, neurocognitive deficits might be present which limit their ability to cooperate [27]. The both locally confined and countrywide outbreaks of HIV transmission by IDU need quite differently structured prevention campaigns than those regarding the sexual transmission of HIV [28]. Apart from IDU, the misuse of "party drugs" in people living with HIV should be addressed by political decision makers [29] [30].

ii) Updated education and prevention campaigns [31] have to focus on people who engage in risky sex with the wrong perception that the HIV-infection is no longer a relevant concern due to cART.

iii) However, without the cooperation of these people with previous and updated prevention campaigns, the goal of the UNAIDS project can hardly be achieved.

3) Diagnosis

Global, as well as local and official institutions, demand better strategies for HIV testing as early as possible after the acquisition of HIV. This management is to offer cART to the HIV-positive tested people, provide them with counseling and link them to health care providers [32]. Furthermore, this claim results from the high parts of people living unaware of their HIV infection for years and spreading HIV depending both on their lifestyles and concentration of HIV in blood. Many of them get tested very late (late diagnosis) in the course of their HIV infection, mostly referred to as late presenters [33] [34] [35]. The late presenters are a consequence of the non-implementation of contact-tracing to identify HIV-positive index patients, thereby favoring the non-disclosure of his/her HIV-positive status to partner/s. People unaware of their HIV infection create the particular situation of already long time established HIV reservoirs in latently infected cells which contain replication-competent HIV genomes but not accessible to cART [36] [37] [38]. In the context of the various forms of late presenters the HIV-related neurocognitive disorders [39] require urgent considerations on consequences for preventive counseling. In particular, people belonging to the late presenters for various reasons counteract the goal of the UNAIDS 90-90-90. Projects have to be developed to improve this situation. The availability of point of care testing turned out to be accepted in young people. [40] A widely unnoticed barrier to HIV testing is that many people feel ashamed of the stigma of HIV, being attached to the state of the exceptionalism of HIV. Point of Care testing facilities should use advanced HIV-tests [41]. 


\section{4) HIV Care}

Offers for HIV care have to be extended [32]. Having HIV patients in "retention to health care" then they can benefit from advising and control of adherence to medications, cART, and other necessary ones. But it turned out that the circumstances to motivate HIV patients to cooperate here have to be structured to the very individual needs to help them [42]. Enforcing the linking to health care for HIV patients seems to be a necessary thing to do [43] [44]. A dire situation is given with people living with HIV/AIDS (PLWH) who know their HIV-positive status but do not initiate cART [45]. Depending on their share, they can pose a critical threat to the transmission of HIV in their communities, apart for the adverse health consequences for themselves. They should be in the special care of HIV providers. ${ }^{6}$

5) Biomedical Approaches with Antiretroviral Drugs (Combination Antiretroviral Therapy, cART)

This concept, based on early test and therapy with cART, proved to be a breakthrough for immune reconstitution when consistently followed [46]. However, interruption of cART entails rebound of HIV viral load to infectious levels [47]. The analysis of Drews et al. [48] attests the requirement of the "health care continuum" for people living with HIV [49]. High standards of awareness for "precision medicine for ART" should be followed [50]. This concept also includes the approaches via the Pre-Exposure Prophylaxis (PrEP) [51] [52]. New developments for injectable antiretroviral drugs that remain active for several weeks show encouraging acceptance. However, the use of PrEP also reveals the outrageous outcomes of high-risk behavior of substance using people when taking PrEP: avoiding HIV infection at the expense of increasing STIs [53].

\section{Conclusions}

1) The Retrospective Shows:

a) Reliance, based on exclusively liberal prevention approaching informational self-determination, does not meet the real lifestyles of many people responsible for spreading HIV. HIV voluntary counseling and testing strategy did not have significant success. These approaches did not achieve the expected progress and will not help to bring down HIV infection chains to the required low level; certain kinds of controls adapted to the circumstances are necessary. Many people of those target groups, if left alone, could not meet the requirements, and, in particular, the extremely unswayable ones were unwilling to behave in ways determined by responsibility for their partners and the society from which they received help. The aftermaths of their failed cooperation are reflected in the continued spread of HIV in most countries following the liberal prevention strate-

6"HIV treatment programmes lose their impact if they do not help people engage with medical care after an HIV diagnosis and stay in contact with HIV services. Improving retention and linkage to care is crucial to improving outcomes along the HIV treatment cascade." Access: http://www.aidsmap.com/Retention-and-linkage-to-care/cat/80814/. 
gies discussed here. The reported budget deficits for the UNAIDS project are a further part of the precarious situation. The ECDC/WHO HIV/AIDS surveillance report for Europe shows different European Regions the estimated and reported new HIV infections and HIV diagnoses, respectively [54] (Figure 1).

b) In contrast, i) Sweden have shown how the goals of the UNAIDS 90-90-90 project [55] can be accomplished "... through a five-stage administrative cascade or HIV continuum ..." including accompanying requirements. ii) The steadily declining new HIV (incidence) infection rates in the United Kingdom also reveal a successful strategy based on the same essentials: (1) at least once a year HIV testing for members of the at-risk groups, (2) compliance with health clinics, e.g., GUM, and (3) the pre-exposure prophylaxis (PrEP) [56].

2) What Options Are There to Support Existing Campaigns to Counteract the Continuing Spread of HIV and Other STI?

a) Web pages and other suitable apps used among at-risk populations. They must be publicly sponsored and also to make sure that control over proper messages gets done; it is the way of modern communication meanwhile.

b) Offers for HIV testing need to be stepped up: A wide range of facilities to cope with the enormous differences and demands of people looking for appropriate confidential testing opportunities.

c) HIV testing should become a duty for the at-risk populations at least within half year terms. Regular HIV testing must become the norm for at-risk individuals.

d) Non-disclosure of HIV-status? Disclosure of his/her HIV status to partners has to be a duty.

e) The late presenters are a result of a not implemented contact-tracing strategy of newly HIV-positive tested people and the non-disclosure of HIV to partners:

Therefore, contact-tracing of HIV infected people and the disclosure of one's HIV-positive status to partners must become a standard of regulations to interrupt the HIV infection chains.

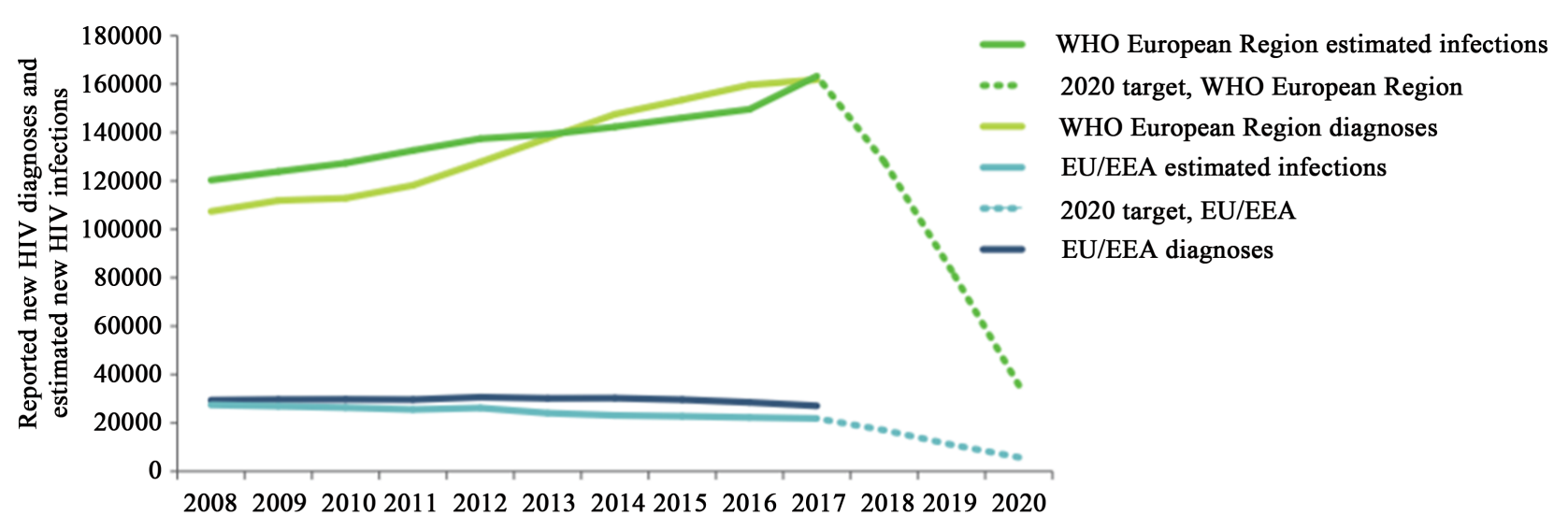

Source: estimated infections, UNAIDS (7); new diagnoses, authors.

Figure 1. Estimated new HIV infections and reported new HIV diagnoses in the EU/EEA and WHO European Region, 2008-2017, and target for 2020. From [54]. 
f) Linking and adherence of HIV patients to health care settings seem to be useful measures.

g) After a transitional period, during the updated education and prevention campaigns are publicly disseminated, new HIV-infected people have to reckon with coercive measures/consequences, such as additional payments for the costs for drug/ART.

h) The messages of the new campaigns concerning safe sex and safe use have to be followed: No recommendations-But duties with/like a legal force.

i) These measures must be part of a concerted campaign.

j) Canceling the status of HIV exceptionalism is necessary to reverse the trauma/stigma of HIV infection.

k) The abused freedoms and the consequences-Not just by a few unswayable people-Have become a mass phenomenon. As a result of this development, the financial burdens on healthcare, social welfare institutions and other businesses are currently unpredictable.

1) A relevant issue in this context concerns the refusal of many "key populations" to respect the principles of social responsibility and to follow the correct messages of prevention campaigns.

m) How do governments justify these challenges to society-Although this person-to-person bound infection is mostly avoidable if the people concerned follow the correct messages of the HIV prevention campaigns?

\section{Conflicts of Interest}

The authors declare no conflicts of interest regarding the publication of this article.

\section{References}

[1] UN News (2018) Prevention Crisis' Is Hampering Global HIV Response, Warns Head of UNAIDS. https://news.un.org/en/story/2018/07/1015042

[2] Kelland, K. (2018) Europe's HIV Epidemic Growing at Alarming Rate, WHO Warns.

https://www.reuters.com/article/us-health-europe-aids/europes-hiv-epidemic-growi ng-at-alarming-rate-who-warns-idUSKBN1DS0W8

[3] Cohen, J. (2018) Russia’s HIV/AIDS Epidemic Is Getting Worse, Not Better. https://www.sciencemag.org/news/2018/06/russia-s-hivaids-epidemic-getting-worse -not-better https://doi.org/10.1126/science.aau4003

[4] Merson, M. and Inrig, S. (2018) Containing the Global Spread of HIV. In: Merson, M. and Inrig, S., Eds., The AIDS Pandemic, Chapter 10, Springer International Publishing, Berlin, 171-196. https://doi.org/10.1007/978-3-319-47133-4 https://link.springer.com/content/pdf/10.1007\%2F978-3-319-47133-4_10.pdf

[5] European Centre for Disease Prevention and Control/WHO Regional Office for Europe (2017) HIV/AIDS Surveillance in Europe 2017-2016 Data. ECDC, Stockholm.

http://www.euro.who.int/_data/assets/pdf_file/0007/355570/20171127-Annual_HI V_Report.pdf?ua $=1$ 
[6] Medicines Sans Frontiers (2018) UNAIDS Report Overlooks Significant Aspects of the Global HIV Response.

https://www.msf.org/unaids-report-overlooks-significant-aspects-global-hiv-respon se

[7] UNAIDS Data 2018.

http://www.unaids.org/sites/default/files/media_asset/unaids-data-2018_en.pdf

[8] WHO (2018) Why the HIV Epidemic Is Not Over.

http://www.who.int/hiv-aids/latest-news-and-events/why-the-hiv-epidemic-is-notover

[9] UNAIDS (2002) Criminal Law, Public Health and HIV Transmission: A Policy Options Paper. UNAIDS/02.12E.

http://data.unaids.org/publications/irc-pub02/jc733-criminallaw_en.pdf

[10] Barré-Sinoussi, F., Abdool Karim, S.S., Albert, J., Bekker, L.G., Beyrer, C., Cahn, P., Godfrey-Faussett, P., et al. (2018) Expert Consensus Statement on the Science of HIV in the Context of Criminal Law. Journal of the International AIDS Society, 21, e25161. https://doi.org/10.1002/jia2.25161

[11] European Centre for Disease Prevention and Control (ECDC) (2017) Evidence Brief: HIV and Laws and Policies in Europe. Monitoring Implementation of the Dublin Declaration on Partnership to Fight HIV/AIDS in Europe and Central Asia. ECDC, Stockholm.

https://ecdc.europa.eu/sites/portal/files/documents/Dublin-EB-HIV\%20and\%20law s\%20and\%20policies\%202017\%20final.pdf

[12] WHO Europe (2004) Dublin Declaration on Partnership to Fight HIV/AIDS in Europe and Central Asia.

http://www.euro.who.int/en/health-topics/communicable-diseases/hivaids/policy/g uid-

ing-policy-documents-and-frameworks-for-whoeuropes-work-on-hiv/dublin-decla ration-on-partnership-to-fighthivaids-in-europe-and-central-asia

[13] Sah, P., Fitzpatrick, M.C., Pandey, A. and Galvani, A.P. (2017) HIV Criminalization Exacerbates Subpar Diagnosis and Treatment across the United States: Response to the "Association of HIV Diagnosis Rates and Laws Criminalizing HIV Exposure in the United States". AIDS, 31, 2437-2439.

https://doi.org/10.1097/QAD.0000000000001636

[14] Dennin, R.H. Sinn, A. and Du, Z. (2018) The Disregarded HIV Prevention Strategies-Their Potential to Uphold the Pandemic, and the Challenges Facing Societies. World Journal of AIDS, 8, 137-159. https://doi.org/10.4236/wja.2018.84011

[15] Hughes, A.J., Rector, A., Jimenez, V., Brock, J. and Scheer, S. (2018) Cumulative Plasma HIV Burden Disparities among Adults in HIV Care: Implications for HIV Transmission in the Era of Treatment as Prevention. AIDS, 32, 1881-1889. https://doi.org/10.1097/QAD.0000000000001914

[16] UNAIDS Global HIV \& AIDS Statistics-2018 Fact Sheet. http://www.unaids.org/en/resources/fact-sheet

[17] European Centre for Disease Prevention and Control (2015) HIV and STI Prevention among Men Who Have Sex with Men. ECDC, Stockholm.

[18] Gourlay, A., Fox, J., Gafos, M., Fidler, S., Nwokolo, N., Clarke, A., Gilson, R., Orkin, Collins, S., Porter, K. and Hart, G. (2017) A Qualitative Study Exploring the Social and Environmental Context of Recently Acquired HIV Infection among Men Who Have Sex with Men in South-East England. BMJ Open, 7, e016494.

https://doi.org/10.1136/bmjopen-2017-016494 
[19] Sosa-Rubí, S.G., Salinas-Rodríguez, A., Montoya-Rodríguez, A.A. and Galárraga, O. (2018) The Relationship between Psychological Temporal Perspective and HIV/STI Risk Behaviors among Male Sex Workers in Mexico City. Archives of Sexual Behavior, 47, 1551-1563. https://doi.org/10.1007/s10508-017-1123-1

[20] Porter, K., Gourlay, A., Attawell, K., Hales, D., Supervie, V., et al. (2018) Substantial Heterogeneity in Progress toward Reaching the 90-90-90 HIV Target in the WHO European Region. JAIDS Journal of Acquired Immune Deficiency Syndromes, 79, 28-37. https://doi.org/10.1097/QAI.0000000000001761

[21] Schrimshaw, E.W., Downing, M.J. and Cohn, D.J. (2018) Reasons for Non-Disclosure of Sexual Orientation among Behaviorally Bisexual Men: Non-Disclosure as Stigma Management. Archives of Sexual Behavior, 47, 219-233. https://doi.org/10.1007/s10508-016-0762-y

[22] Robert Koch Institute (2018) Syphilis in Deutschland im Jahr 2017-Anstieg von Syphilis-Infektionen bei Männern, die Sex mit Männern haben, setzt sich weiter fort. Epidemiologisches Bulletin, 46, 493-504. (In German)

[23] Pradat, P., Huleux, T., Raffi, F., Delobel, P., Valantin, M., Poizot-Martin, I., Pugliese, P., Reynes, J., Rey, D., Hoen, B., Cabie, A., Bani-Sadr, F., Cheret, A., Duvivier, C., Jacomet, C., Fresard, A., Hustache-Mathieu, L., Cotte, L. and Dat' AIDS Study Group (2018) Incidence of New Hepatitis C Virus Infection Is Still Increasing in French MSM Living with HIV. AIDS, 32, 1077-1082.

https://doi.org/10.1097/QAD.0000000000001789

[24] Oriolo, G., Egmond, E., Mariño, Z., Cavero, M., Navines, R., Zamarrenho, L., Solà, R., Pujol, J., Bargallo, N., Forns, X. and Martin-Santos, R. (2018) Systematic Review with Meta-Analysis: Neuroimaging in Hepatitis C Chronic Infection. Alimentary Pharmacology \& Therapeutics, 47, 1238-1252. https://doi.org/10.1111/apt.14594

[25] Brockmeyer, N.H. (2017) Sexualität \& Psyche, 2017, Bochum. https://www.my-micromacro.net/mymicromacro-ist-ausgezeichnet

[26] AVERT:31.08.18: Empowering People through Knowledge. The HIV Prevention Crisis-Increasing Knowledge through Innovation.

[27] Harris, M., et al. (2018) Associations of Loneliness with Cognitive Function and Quality of Life (QoL) among Older HIV+ Adults. 9th International Workshop on HIV \& Aging, New York, 13-14 September 2018.

[28] Des Jarlais, D., Sypsa, V., Wiessing, L., et al. (2018) Complacency Is the New Problem: Comparative Analysis of Recent Outbreaks of HIV among Persons Who Inject Drugs in Europe and North America. 22nd International AIDS Conference, Amsterdam, 23-27 July 2018, Abstract THPEC189.

[29] Bracchi, M., Stuart, D., Castles, R., Khoo, S., Back, D. and Boffito, M. (2015) Increasing Use of "Party Drugs" in People Living with HIV on Antiretrovirals: A Concern for Patient Safety. AIDS, 29, 1585-1592. https://doi.org/10.1097/QAD.0000000000000786

[30] Giorgetti, R., Tagliabraccia, A., Schifanob, F., Zaamic, S., Marinellic, E. and Busardòc, F.P. (2017) When "Chems" Meet Sex: A Rising Phenomenon Called “ChemSex". Current Neuropharmacology, 15, 762-770. https://doi.org/10.2174/1570159X15666161117151148

[31] Schneider, J.A. and Bouris, A.M. (2017) Emerging and Innovative Prevention Strategies for HIV Positive Gay Men. In: Wilton, L., Ed., Understanding Prevention for HIV Positive Gay Men, Springer, New York, 193-221. https://doi.org/10.1007/978-1-4419-0203-0_8

[32] Drew, R.S., Rice, B., Rüütel, K., Delpech, V., Attawell, K.A., Hales, D.K., Velasco, C., 
Amato-Gauci, A.J., Pharris, A., Tavoschi, L. and Noori, T. (2017) HIV Continuum of Care in Europe and Central Asia. HIV Medicine, 18, 490-499. https://doi.org/10.1111/hiv.12480

[33] Jiang, H., Xie, N., Liu, J., Zhang, Z., Liu, L., Yao, Z., Wang, X. and Nie, S. (2015) Late HIV Diagnosis: Proposed Common Definitions and Associations with Short-Term Mortality. Medicine (Baltimore), 94, e1511. https://doi.org/10.1097/MD.0000000000001511

[34] Cheng, W., Tang, W., Han, Z., et al. (2016) Late Presentation of HIV Infection: Prevalence, Trends, and the Role of HIV Testing Strategies in Guangzhou, China, 2008-2013. Journal of Biomedicine and Biotechnology, 2016, Article ID 1631878. https://doi.org/10.1155/2016/1631878

[35] Hu, H., Yan, H., Liu, X., Xu, X., Xu, J., Qiu, T., Shi, L., Fu, G., Huan, X., McFarland, W. and Wei, Ch. (2017) Trends in Late HIV Diagnosis among Men Who Have Sex with Men in Jiangsu Province, China: Results from Four Consecutive Community-Based Surveys, 2011-2014. PLoS ONE, 12, e0172664.

https://doi.org/10.1371/journal.pone.0172664

[36] Harper, K.N. (2017) A Decade of Learning about the HIV Reservoir: New Insights into Latent Infection. AIDS, 31, N19-N20. https://doi.org/10.1097/QAD.0000000000001559

[37] Brumme, Z., Sudderuddin, H., Ziemniak, C., Luzuriaga, K., Jones, B.R., Joy Jeffrey, B., Cunningham, C.K., Greenough, Th. and Persaud, D. (2018) Genetic Complexity in the Replication-Competent Latent HIV Reservoir Increases with Untreated Infection Duration in Infected Youth. AIDS, 33, 211-218. https://doi.org/10.1097/QAD.0000000000002045

[38] Dailey, A.F., Hoots, B.E.H., Hall, I., Song, R., Hayes, D., Fulton Jr., P., Prejean, J., Hernandez, A.L., Koenig, L.J., Valleroy, L.A., et al. (2018) Vital Signs: Human Immunodeficiency Virus Testing and Diagnosis Delays-United States. Morbidity and Mortality Weekly Report, 66, 1300-1306.

https://doi.org/10.15585/mmwr.mm6647e1

[39] Sanfilippo, C., Pinzone, M.R., Cambria. D., Longo, A., Palumbo, M., Di Marco, R., Condorelli, F., Nunnari, G., Malaguarnera, L. and Di Rosa, M. (2018) OAS Gene Family Expression Is Associated with HIV-Related Neurocognitive Disorders. Molecular Neurobiology, 55, 1905-1914. https://doi.org/10.1007/s12035-017-0460-3

[40] Turner S.D., Anderson, K., Slater, M., Quigley, L., Dyck, M., Guiang, C.B., et al. (2103) Rapid Point-of-Care HIV Testing in Youth: A Systematic Review. Journal of Adolescent Health, 53, 683-691. https://doi.org/10.1016/j.jadohealth.2013.07.029

[41] Gray, E.R., Bain, R., Varsaneux, O., Peeling, R.W., Stevens, M.M. and McKendry, R.A. (2018) p24 Revisited: A Landscape Review of Antigen Detection for Early HIV Diagnosis. AIDS, 32, 2089-2102. https://doi.org/10.1097/QAD.0000000000001982

[42] Ruben, M.A. and Fullerton, M. (2018) Proportion of Patients Who Disclose Their Sexual Orientation to Healthcare Providers and Its Relationship to Patient Outcomes: A Meta-Analysis and Review. Patient Education and Counseling, 101, 1549-1560. https://doi.org/10.1016/j.pec.2018.05.001

[43] Jones, D.L., Sued, O., Cecchini, D., Bofill, L., Cook, R., Lucas, M., Bordato, A., Cassetti, I., Cahn, P. and Weiss, S.M. (2016) Improving Adherence to Care among "Hard to Reach" HIV-Infected Patients in Argentina. AIDS and Behavior, 20, 987-997. https://doi.org/10.1007/s10461-015-1133-8

[44] Hogg, R.S. (2018) Phylogenetic Analyses of Local HIV Transmission. The Lancet $H I V$, 5, e270-e271. https://doi.org/10.1016/S2352-3018(18)30102-4

[45] Ahmed, S., Autrey, J., Katz, I.T., Fox, M.P., Rosen, S., Onoya, D., Bärnighausen, T., 
Mayer, K.H. and Bor, J. (2018) Why Do People Living with HIV Not Initiate Treatment? A Systematic Review of Qualitative Evidence from Low- and Middle-Income Countries. Social Science \& Medicine, 213, 72-84. https://doi.org/10.1016/j.socscimed.2018.05.048

[46] Roul, H., Mary-Krause, M., Ghosn, J., Delaugerre, C., Pialoux, G,, Cuzin, L., Launay, O., Lacombe, J.M., Menard, A., De Truchis, P., Delfraissy, J.F., Weiss, L., Costagliola, D. and FHDH-ANRS CO4 (2018) CD4 ${ }^{+}$Cell Count Recovery after Combined Antiretroviral Therapy in the Modern Combined Antiretroviral Therapy Era. AIDS, 32, 2605-2614.

[47] Palich, R., Ghosn, J., Chaillon, A., Boilet, V., Nere, M.L., Chaix, M.L., Delobel, P., Molina, J.M., Lutch, F., Bouchaud, O. , Rieux, V., Thiebaut, R., Levy, Y., Delaugerre, C., Lelievre, J.D. and VRI02/ANRS149 LIGHT Vaccine Trial Group (2018) Viral Rebound in Semen after Antiretroviral Treatment Interruption in an HIV Therapeutic Vaccine Double-Blind Trial. AIDS, 33, 279-284. https://doi.org/10.1097/QAD.0000000000002058

[48] Drew, R.S., et al. (2017) HIV Continuum of Care in Europe and Central Asia. HIV Medicine, 18, 490-499. https://doi.org/10.1111/hiv.12480

[49] Wu, Z., Tang, Z., Mao, Y., et al. (2017) Testing and Linkage to HIV Care in China: A Cluster-Randomised Trial. The Lancet, 4, e55-e56.

[50] Mu, Y., Kodidela, S., Wang, Y., Kumar, S. and Cory, T.J. (2018) The Dawn of Precision Medicine in HIV: State of the Art of Pharmacotherapy. Expert Opinion on Pharmacotherapy, 19, 1581-1595. https://doi.org/10.1080/14656566.2018.1515916

[51] Zablotska, I.B. and O’Connor, C.C. (2017) Preexposure Prophylaxis of HIV Infection: the Role of Clinical Practices in Ending the HIV Epidemic. Current HIVIAIDS Reports, 14, 201-210. https://doi.org/10.1007/s11904-017-0367-7

[52] Holt, M., Lea, T., Mao, L., Kolstee, J., Zablotska, I., Duck, T., Allan, B., West, M., Lee, E., Hull, P., Grulich, A., De Wit, J. and Prestage, G. (2018) Community-Level Changes in Condom Use and Uptake of HIV Pre-Exposure Prophylaxis by Gay and Bisexual Men in Melbourne and Sydney, Australia: Results of Repeated Behavioural Surveillance in 2013-17. The Lancet HIV, 5, e448-e456. https://doi.org/10.1016/S2352-3018(18)30072-9

[53] Hoenig, M, Jain, S., Moore, D., Collins, D., Sun, X., Anderson, P.L. and Morris, S. (2018) Substance Use and Adherence to HIV Preexposure Prophylaxis for Men Who Have Sex with Men. Emerging Infectious Diseases, 24, 2292-2302. https://doi.org/10.3201/eid2412.180400

[54] European Centre for Disease Prevention and Control, WHO Regional Office for Europe (2018) HIV/AIDS Surveillance in Europe 2018-2017 Data.

https://ecdc.europa.eu/en/publications-data/hivaids-surveillance-europe-2018-2017 -data

[55] Gisslen, M., Svedhem, V., Lindborg, L., Flamholc, L., Norrgren, H., Wendahl, S., Axelsson, M. and Sonnerborg, A. (2017) Sweden, the First Country to Achieve the Joint United Nations Programme on HIV/AIDS (UNAIDS)/World Health Organization (WHO) 90-90-90 Continuum of HIV Care Targets. HIV Medicine, 18, 305-307. https://doi.org/10.1111/hiv.12431

[56] Public Health England (2018) Progress towards Ending the HIV Epidemic in the United Kingdom: 2018 Report.

https://assets.publishing.service.gov.uk/government/uploads/system/uploads/attach ment_data/file/759408/HIV_annual_report_2018.pdf 